\title{
Technology Transfer: Fighting Climate Change and Pursuing Equity Through the Transfer of Energy Efficient and Renewable Energy Technologies
}

Craig M. Scott

Osgoode Hall Law School of York University

Follow this and additional works at: https://digitalcommons.osgoode.yorku.ca/all_papers

Part of the Environmental Law Commons

\section{Repository Citation}

Scott, Craig M., "Technology Transfer: Fighting Climate Change and Pursuing Equity Through the Transfer of Energy Efficient and Renewable Energy Technologies" (1991). All Papers. 331.

https://digitalcommons.osgoode.yorku.ca/all_papers/331

This Article is brought to you for free and open access by the Research Papers, Working Papers, Conference Papers at Osgoode Digital Commons. It has been accepted for inclusion in All Papers by an authorized administrator of Osgoode Digital Commons. 


\title{
Technology Transfer: Fighting Climate Change and Pursuing Equity Through the Transfer of Energy Efficient and Renewable Energy Technologies
}

\author{
Original paper: August 14, 1991 \\ (this cover page, April 19, 2021) \\ Craig Scott, Professor of Law, Osgoode Hall Law School* \\ Prepared in advance of the 1992 Río de Janeiro Earth Summit on behalf of Friends of the \\ Earth (Indonesia), Friends of the Earth (Ghana) and Friends of the Earth (Canada) ${ }^{\Omega}$ \\ with the assistance of \\ Robert Hornung (FOE/Canada) \\ Agus Purnamo (FOE/Indonesia) \\ Agus Sari (FOE/Indonesia) \\ Emmy Hafild (FOE/Indonesia) \\ Douglas Korsah-Brown (FOE/Ghana)
}

- This report was written in 1991 when Prof. Scott was Assistant Professor of Law at the University of Toronto. He is currently Professor of Law at Osgoode Hall Law School of York University, Toronto, which he joined in 2000. It is being made available now, mostly as an exercise in historical documentation but also on the slight possibility that any of the reasoning and recommendations might yet have some relevance as the world, 30 years later, has failed to attend to the climate emergency that the report already took as its premise back in 1991. Prof. Scott is the principal author and Robert Hornung edited the text. The document did not reflect the views of Friends of the Earth International at the time written, being an initiative of three national sections. A fortiori, it may reflect the views of no FOE section 30 years later, given how many changes there will have been in discussions and mechanisms for transfer of environmental technology.

$\Omega$ Although "finalized" from the perspective of Prof. Scott's role, the report was also labelled "Draft" so as to enable the various FOE chapters alongside FOE International to modify if and as they desired in the lead-up to the Earth Summit. Prof. Scott does not have specific recall of what use was made of the report before, during and after either the official Earth Summit (of states) that led to the 1992 Climate Change Convention or at the Alternative Earth Summit of transnational civil society actors that ran in parallel to the Earth Summit. 
ABSTRACT

\title{
Technology Transfer: Fighting Climate Change and Pursuing Equity Through the Transfer of Energy Efficient and Renewable Energy Technologies
}

\author{
Original paper: August 14, 1991
}

\section{Craig Scott, Professor of Law, Osgoode Hall Law School}

The present paper was prepared in the first half of 1991 in collaboration with three national sections of Friends of the Earth (Indonesia, Ghana and Canada). It was written by Craig Scott, with input and feedback from each section, and then edited by Robert Hornung. The purpose of the paper was to provide a discussion document of a "white paper" sort that could be used, as seen fit by Friends of the Earth and allied civil society organizations, in the advocacy efforts before, during and after either the official Earth Summit (of states) in Rio de Janeiro that led to various instruments including the 1992 Climate Change Convention - and/or used during the Alternative Earth Summit of transnational civil society actors that ran in parallel to the Earth Summit. The paper is being made available now, mostly as an exercise in historical documentation but also on the possibility that any of the reasoning and recommendations might yet have some relevance as the world, 30 years later (in the immediate lead-up to the lastchance Conference of the Parties in the United Kingdom in fall 2021), has failed to attend to the climate emergency that the report already took as its premise back in 1991.

The paper's title captures well the focus of the paper. It is an exercise in setting out key principles of institutional design in view of the competition between moral philosophies of global environmental justice and dominant economic theories and associated state policy. It begins with an overview of the history, as of 1991, of general transfer-of-technology (TOT) South/North dynamics and then situates debate surrounding transfer-of-environmentaltechnology (TOET) as it had developed up to and within the negotiations around the Climate Change Convention. It proceeds to discuss a trio of goals that must be achieved with any climaterelated TOET regime and then fleshed out key principles applicable on four issues: decisionmaking power and control; sources of financing; nature of normative commitments; and shape and extent of intellectual property rights. The second half of the paper then presents and discusses four ideal-type models for a climate-change TOET mechanism or regime and concludes with an argument for a hybrid regime that has features of the first three models discussed. The reasoning surrounding the recommended regime may yet be relevant to some of the decisions to come at COP 2021. 
Technology Transfer:

Fighting Climate Change and Pursuing Equity Through the Transfer of Energy Efficient and Renewable Energy Technologies

Friends of the Earth Canada

Friends of the Earth Ghana

WALHI (Friends of the Earth Indonesia)

August 14, 1991

DRAFT DRAFT DRAFT DRAFT DRAFT DRAFT DRAFT DRAFT DRAFT DRAFT

** The principal author in the production of this report was Mr. Craig Scott, Assistant Professor in the Faculty of Law at the University of Toronto. It was edited by Robert Hornung (Friends of the Earth Canada) and received significant contributions from Agus Purnomo, Agus Sari and Emmy Hafild (WALHI), as well as Douglas Korsah-Brown (Friends of the Earth Ghana). This publication is not in any way meant to reflect the views of Friends of the Earth International. *** 


\section{I. . INTRODUCTION}

Scientists have come to a consensus that the emission of greenhouse gases into the atmosphere, if left unchecked, will increase the average temperature of the earth at a rate faster than seen any time in the last 10,000 years. Such a rapid increase will lead to dramatic climate change, with devastating impacts for all life on the planet.

Fighting this "global warming" requires that we reduce our emission of greenhouse gases, like carbon dioxide, into the atmosphere. At the present time, the majority of anthropogenic carbon dioxide emissions comes from the burning of fossil fuels for energy.

Seventy-five percent of such emissions currently come from industrialized countries, and the historical contribution is even higher. Per capita emissions from these sources are also much higher in the North than in the South. Moreover, the energy producing these emissions has fuelled economic growth in the North and created a massive income gap between industrialized and developing countries.

If climate change is to be avoided; industrialized countries must reduce their emissions of carbon dioxide by a minimum of 20 to 30 percent in the next decade and by much more than 60 percent in the longer term. Such action is necessary on both ethical and environmental grounds.

Even so, these measures in industrialized countries may not be enough to protect the global climate. It is likely that Southern countries will require a substantial increase in their energy use in order to pursue their legitimate economic development goals. If this were to lead to a correspondingly large increase in Southern greenhouse gas emissions, serious climate change would be unavoidable.

Fortunately, there need not be a strong link between economic growth and increased greenhouse gas emissions from energy use. The road to economic development pursued by Northern countries is not the only path available. More efficient use of energy and a greater reliance on non-polluting renewable energy sources can make a difference.

Many technologies are already available to support this alternative development path and the pace of technological innovation is accelerating. Most of the research and development ( $R \& D$ ) work has been, and continues to be, done in the North. The transfer of these technologies to the South, and the creation of an indigenous capacity in the South to adapt these technologies and develop new ones, will be essential if we are to ensure that the legitimate development aspirations of Southern countries are to proceed in harmony with the global climate.

Negotiators are currently striving to create a Framework Convention on Climate Change for signature at the United Nations' Conference on Environment and Development in 1992. Technology transfer is an important focus of these discussions but agreement in this area will be difficult to achieve. It is likely, however, that a meaningful response to global warming will require the establishment of a precedent 
setting mechanism that will play an important role in defining the character of NorthSouth relations in the post-1992 world.

This paper attempts to take a position on technology transfer and the broad type of mechanism that should be included in a climate change convention to pursue that goal.

\section{THE HISTORY OF TRANSFER OF TECHNOLOGY}

\section{a) Transfer of Technology (TOT) as a Generic Issue}

Well before any focus arose at the international level on transferring environmental technology, a fierce debate had begun on the issue of transfer of technology in a generic sense. It emerged in the late 1960s as a core component of the package of changes countries of the South (or the Group of 77) sought to have. implemented as part of the New International Economic Order (NIEO). The centrality of the need to transfer technology was based on economic analyses that isolated a technology gap between states as a crucial factor in keeping rich countries rich and poor countries poor.

The debate was characterized on both sides by appeals to morality. Southern countries spoke of a moral right of states to technology because scientific knowledge and the resulting technological discoveries were best conceptualized as part of the common heritage of humanity. This view was countered by the affluent countries and their corporations with the argument that technology was primarily a matter of private interest and that individuals had moral rights to intellectual property protection that ensured they would benefit from the fruits of their work. These countries also claimed that, without intellectual property (IP) protection, the incentive to innovate would disappear.

With these two battle positions taken, North and South have skirmished in a number of different international fora over the last twenty years primarily over the terms on which countries in the South could have technology transferred to them by companies (and, to a more limited extent, countries) in the North.

The best-known context has been the negotiations within UNCTAD on a Code of Conduct on the Transfer of Technology, although this debate has also figured prominently during the negotiation of the Law of the Sea Convention and is now even a central feature (through intellectual property rights) of discussions to amend the General Agreement on Tariffs and Trade (GATT).

All of these negotiations have failed to resolve the technology transfer debate. Results have been minimal. The UNCTAD talks continue, the Law of the Sea Convention has yet to enter into force and the current Uruguay Round of the GATT is in serious trouble. Indeed, it is only with reference to the transfer of environmental technology that some modest progress has been made. 
b) Transfer of Environmental Technology (TOET) in Evolving Global Environmental Policy and Law

As the debate has moved into specific global environmental issues, the argumentation has changed somewhat. Primarily, the industrialized countries have recognized that they have some degree of self-interest in the transfer of technology designed to help resolve a global environmental problem. Reciprocity of interest is thus likely to be a more salient factor in TOET negotiations than it has been in the generic TOT debate.

Even so, few international environmental agreements refer to technology transfer and those that do are fairly recent. One of these is the 1989 NOx Protocol to the ECE's 1979 Convention on Long-range Transboundary Air Pollution (LRTAP) and another is the African Convention on the Ban of the Import of all Forms of Hazardous Wastes into Africa, which offers the first example of a substantive provision on South-South TOET.

But in terms of concrete models to turn to, the recent June 1990 amendment to the 1987 Montreal Protocol to the Vienna Convention for the Protection of the Ozone Layer is clearly the most instructive. This amendment has broken new ground on the technology transfer issue and it is discussed in detail later in this paper where it forms the basis for two of the technology transfer models analyzed.

At this time, it remains impossible to offer an assessment of the effectiveness of this technology transfer mechanism. The first year of its existence has been dominated the bureaucratic and administrative issues that required resolution before technology transfer could proceed. It should be clear by the time of the UNCED conference whether this experience will be a positive or negative one.

c) Rhetoric Surrounding the Transfer of Environmental Technology Within the Context of the Climate Change Convention Negotiations

Virtually without exception, all government declarations and model climate change convention formulations have identified the transfer of technology as a critical element element that is required on environmental grounds. These texts also recognize that industrialized countries have a special ethical responsibility to transfer technologies to the South because Northern economic development has been the major source of the carbon dioxide emissions that now threaten the planet with climate change and has led to massive inequality between North and South.

For example, the Ministerial Declaration from the Second World Climate Conference (October-November 1990) states that "the developed world is responsible for about 3/4 of all emissions of greenhouse gases": (para.12) and "(n)arrowing the gap between the developed and developing world would provide a basis for a full partnership of all nations and would assist the developing countries in dealing with the climate change issue" (para.15). 
These considerations then grounded the following recommendation in the declaration: "To enable developing countries to meet incremental costs required to take the necessary measures to address climate change...we recommend that adequate and additional financial resources should be mobilized and best available environmentally sound technologies transferred expeditiously on a fair and most favourable basis" (section 15).

While it is clear that the international community recognizes on a rhetorical level that a commitment by industrialized countries to transfer technology and provide additional funding towards this end is inescapable in a climate change convention, it remains unclear what mechanism should be used to make this commitment a reality.

The main report of the Intergovernmental Panel on Climate Change (IPCC) frankly admitted that there remains a huge gap between some Southern countries that want a non-commercial transfer of technology promoted by specific arrangements at the state-to-state level and Northern countries that believe technology transfer remains a matter solely for commercial negotiation in a context in which there is full protection of intellectual property rights.

Accordingly, the climate change convention negotiations provide yet another opportunity to resolve a debate that has characterized North-South relations for over 20 years.

\section{DEFINITIONS AND FUNDAMENTAL GOALS AND PRINCIPLES}

The negotiators of a climate change convention can experiment with a wide range of possible technology transfer mechanisms in their search for an agreement. Before assessing some of these options, it is important for us to define what we mean by the term technology transfer and it is also critical to describe the fundamental goals and principles that we believe must underlie any technology transfer mechanism.

Technology transfer is definitely a term that means different things to different people. In the context of energy related carbon dioxide emissions and climate change, technology transfer has three key components for us:

a) the transfer of machinery or equipment, including computer software, that either directly reduces the carbon dioxide emissions. resulting from energy production and use or provides the means to produce such machinery or equipment;

b) the transfer of knowledge and skills relating to the reduction of carbon dioxide emissions from energy production and use;

c) the transfer of resources to support the development of an indigenous capacity to research and manufacture technologies that will reduce carbon dioxide emissions from energy production and use. 
It is important to note that we believe that a technology transfer mechanism should not only exist to transfer these components from North to South. South-toSouth transfers must also be promoted and support of indigenous technological development in the South will help facilitate South-to-North transfers as well.

Moreover, the technology that is transferred must be appropriate to the receiver's local resources, needs and culture. A failure to heed this simple point has been the key factor in the dismal record of technology transfer to this point in time.

Such technology transfer must have the following goals in our view:

a) reduce carbon dioxide emissions from energy production and use in the North and reduce the rate of growth of these emissions in the South,

b) support and promote sustainable economic development in the North and the South,

c) work towards a world in which the fundamental equality of all human beings is recognized by reducing inequitable living standards between North and South, within North and South, and within individual countries.

Of course, simply noting what technology transfer is and what it should accomplish is not the same as indicating how it should be done. Any possible technology transfer mechanism can have many variations depending on how it deals with such critical issues as who controls the financing, what commitments will be made by governments, where the money comes from and whether or not intellectual property rights should be protected.

Recognizing the environmental and ethical responsibility of industrialized countries to transfer technology, we can set out a number of broad principles that must underlie any technology transfer mechanism developed under a climate change convention:

\section{Principle 1: Control}

The technology transfer mechanism within a climate change convention must provide the governments of Northern and Southern countries with equal decisionmaking power.

Decision-making processes must be open and transparent and an environmental impact assessment that adheres to these democratic principles must also be conducted before technology transfer proceeds.

Access to information and the decision-making process must be provided to all concerned parties, in particular local citizens, NGOs, businesses and governments that will be impacted by the technology. This should be formalized through the creation of a parallel forum for representatives from these sectors. Such a forum should be free to debate proposals considered by government representatives and delay 
decisions by those representatives in order to ensure that the best possible use of the funds is made. This parallel forum must not, however, be allowed to overturn decisions.

A separate mechanism should exist that would allow individuals and organizations affected by a technology transfer funding decision the ability to appeal that decision.

\section{Principle 2: Financing}

The polluter pays principle should be respected. A climate change convention must make it mandatory for all industrialized countries (including those of Central and Eastern Europe) to cover the costs of a technology transfer mechanism with each couritry's contribution determined by its relative contribution to the problem. This funding must be additional to resources already provided by these Northern countries to the countries of the South.

\section{Principle 3: Commitments}

Northern industrialized countries must make binding commitments in a climate change convention to rapid cuts in carbon dioxide emissions and the financing and support of whatever technology transfer mechanism is created within the convention. These commitments must be the cornerstone of any climate change convention.

Eastern and Central European countries must not only contribute, but must also be able to access, the resources of a technology transfer mechanism in order to meet their binding commitments to targets and timetables for the reduction of carbon dioxide emissions.

Developing countries, however, must be treated differently. These countries have historically made only a minor contribution to the emission of greenhouse gases and do not bear the primary responsibility for solving the climate change problem.

Developing countries can make a significant contribution to protecting the global climate by simply making a commitment to use technology transferred to support efforts to reduce carbon dioxide emissions from energy production and use: Technology transfer should ensure that this minimal commitment is met. Binding commitments should also be made to support global scientific efforts to understand the threat posed by climate change.

Beyond that, developing countries should agree to set out non-binding targets and timetables for limiting the growth of carbon dioxide emissions and achieving future levels of economic growth. Implementation of these targets would be assessed by all Parties to a climate change convention on a regular basis in order to determine where further assistance is required from the technology transfer mechanism to ensure that these targets can be met: While these non-binding commitments should characterize the early years of a climate change convention, their usefulness should be assessed several years into the process and changes considered if necessary. 
Principle 4: Intellectual Property Rights

The principle of intellectual property rights should receive some form of protection in any technology transfer mechanism associated with a climate change convention. Their value as an incentive and reward for technological development and innovation is especially important for small firms that do not have the resources of a General Motors. As well, the patent system provides a disincentive to the use of techniques of secrecy to protect one's inventions.

This does not mean that corporations should not be encouraged to waive their intellectual property rights in response to a global environmental crisis. For example, members of the Industry Cooperative for Ozone Layer Protection (ICOLP) have already voluntarily agreed to waive their patent rights on any alternatives they develop to the use of ozone-destroying CFCs as a cleaning solvent.

It must be remembered, however, that it is the citizens of industrialized countries who have supported and encouraged their corporations to develop technologies that have become responsible for the vast majority of carbon dioxide emissions arising from energy use and production. Accordingly, developing countries must not bear any burden for rewarding Northern companies who find technological fixes to the global crisis citizens in the industrialized countries have created.

The resources needed to protect intellectual property rights, therefore, must come from industrialized countries and must be additional to funds provided to a technology transfer mechanism. Southern countries must not see their access to the funding required for technology transfer reduced in any way by the protection of intellectual property rights.

\section{ALTERNATIVE MODELS FOR TRANSFER OF ENVIRONMENTAL TECHNOLOGY}

Working from these basic principles, it is now possible to assess alternative mechanisms for technology transfer. This section will examine four different models. Each involves some change of the status quo and some kind of role for multilateral regulation; each is potentially a complete approach to the transfer of technology issue; and each can be said to have transfer of technology as either the reason or one of the central reasons for the scheme.

The goal of this section, given space limitations, is to present a basic, but hopefully sufficient, discussion of the model and then briefly to identify its major strengths and weaknesses. A comprehensive assessment of strengths and weaknesses is beyond the scope of this paper. 
Model 1: Following Article 10 of the Montreal Protocol -

Contractual Transfer by Corporations and Financing from an International Fund

\section{Description:}

Article 10 of the revised Montreal Protocol establishes a financial mechanism with a Multilateral Fund "for the purpose of providing financial and technical cooperation, including the transfer of technologies" to developing countries. If Southern countries agree to the Protocol's commitments to phase out ozone-depleting substances, they may apply to this Fund for monies to cover the "incremental cost" of technologies required to meet these commitments.

The industrialized countries contribute to the Fund on the UN scale of assessment, but it is important to note that both Article 10 and the Preamble emphasize that these funds are to be "additional" to other financial 'development' aid Southern countries might receive. The Parties have set up an Interim Financial Mechanism with a three-year budget of $\$ 200$ million ( $\$ 240$ million if India ratifies the Protocol).

The Interim Multilateral Fund is overseen by an Executive Committee made up of 14 Parties to the Protocol, seven from industrialized and seven from developing. countries. Implementation is undertaken by three separate organizations: the World Bank, UNEP and UNDP.

While this Fund is a path-breaking institution, Article 10 says nothing about how and under what terms technology is acquired. This continues to be determined through contractual negotiations between a Northern company and the recipient, public or private, in a Southern country. When agreement has been reached on a contract, the Southern country can then apply to the Fund for money that will allow the transfer to take place, somewhat like seeking a mortgage although by and large involving grants not loans.

This model therefore leaves private contractual relationships and intellectual property rights undisturbed. The private company selling the technology is unconcerned if the purchasing (licensing) Southern state finances the payment for the technology via the Article 10 mechanism or directly out of its own coffers. What is important to note is that it is not required to sell or license its technology until it gets the price and terms it wants.

\section{Strengths and Weaknesses:}

This model would appear to have in its favour its 'practicability', as defined in terms of the North's willingness to accept the model. It would also seem to have the merit of accepting that Northern societies must bear the collective responsibility for paying the price of insistence on protecting private intellectual property rights and maintaining commercial TOET deals as the main transfer mechanism. By maintaining this market system, there can be no argument that incentives are not 
there for corporations to transfer technology.

Another positive aspect of this model is that there is nothing inherent in the mechanism to limit it to a very narrow conception of technology as being simply a physical package (or discrete description in the form of a patent) that one takes off a shelf and transfers. Funding can accommodate any definition, including $R$ \& $D$, training, education (professional as well as popular), and know-how. This model may be particularly effective for the transfer of 'soft' technologies that require significant human interaction because the transfer would be based on a mutually acceptable arrangement between the transferor and the transferee.

That being said, however, there remains nothing in this model that requires companies to transfer technology. This can leave Southern countries and companies at a real disadvantage when negotiating a technology transfer contract. If Southern countries and companies are required to meet any more than the minimum commitments described earlier, and need this technology to do it - they must have a deal. Northern companies, however, can simply walk away if their conditions are not met. They can hold out for higher prices or avoid any commitments on other issues like strengthening indigenous technological capacity.

This reflects the fundamental flaw in this model. It reduces technology transfer to a quantitative, pecuniary notion in the sense that it merely compensates for the price reached in commercial deals. It has no direct interest in the qualitative dimensions of the deals reached, such as how the technology transfer deal adds to the indigenous technological capacity of the South. Also, it has nothing to say about the failure of the South to secure the best available technologies; it simply assumes that what the South has been able to find in the marketplace will be adequate to deal with the problem.

Model 2: Elaborating Article 10A of the Montreal Protocol Direct Acquisition of Technology and Subsequent Transfer by States or Intergovernmental Agency

\section{Description:}

While Article 10 of the Montreal Protocol finances the acquisition of technology through whatever arrangements the Southern state has entered into with technology suppliers, Article 10A seems to envisage transfers in kind directly or indirectly from state to state. This article remains soft, however, with the obligation falling in a dispersed way on each party to "take every practicable step consistent with the programmes supported by the financial mechanism, to ensure: (a) That the best available, environmentally safe substitutes and related technologies are expeditiously transferred to [Southern countries]...; and (b) That the transfers referred to in subparagraph (a) occur under fair and most favourable conditions."

Although Article $10 \mathrm{~A}$ is clearly meant to accomplish something more in terms of technology transfer than can be accomplished simply through the Article 10 financial mechanism (otherwise it would be redundant), nothing in Article 10A 
expressly requires Northern states to acquire the best available technology for transfer if the holder of that technology refuses to do so. The Parties made it known that the content of Article 10A is less than clear when they decided that the Protocol's Openended Working Group would continue : to exist in part to "identif[y]...the most appropriate modalities for the transfer of technologies".

Building upon Article 10A, we can postulate a model where technology transfer is best conceptualized as a transfer in kind from state to state, or through an intergovernmental agency. This model takes a public international sector transfer of technology as its fulcrum with the buyer unconcerned about how the technology was acquired, whether by expropriation, negotiated licensing or compulsory licensing. The basic obligation on the. North is to get the best available, greenhouse-abating technology to countries in the South.

Such an intergovernmental agency could take many forms and have a wide array of powers and responsibilities. For the purposes of this paper, and to make consideration simpler, we will posit an International Technology Transfer Agency (ITTA). The ITTA would be vested with the authority and financial resources to identify technologies and acquire them for transfer or to require individual Northern states to acquire the technology once identified as a global social need and then transfer it either directly or via ITTA.

In essence, this would amount to treating the global (not just national) social interest in greenhouse-abating technology as trumping private interests, although quite obviously private interests are respected to an important degree when an international governmental organization like ITTA pays to acquire the technology for transfer. Indeed, this model would envisage such compensation being fixed at a level judged sufficient to continue to create incentives to innovate.

In functional terms, ITTA would bear some resemblance to the International Deep Seabed Authority under the 1982 Law of the Sea Convention, the Authority having the power to negotiate transfers of technology from mining companies as a condition for their access to the deep sea floor (Art. 5, Annex III). Of course, whereas the global social.interest vindicated by the Authority under the banner of the 'common heritage of humanity' would be (equitable) exploitation of the wealthproducing resources of a global commons, the global social interest of ITTA would be (equitable) protection of another global commons.

\section{Strengths and Weaknesses:}

One of the advantages of this model is that its focus is directly on technology transfer and is qualitative in nature. An organization like the ITTA could seek out the best available technologies and play a very comprehensive and proactive role in making sure that the best achievable pattern of technology transfer (and related indigenous capacity building) takes place with global warming abatement/sustainable development as the guiding rationales. Near-simultaneous multilateral availability would be secured instead of the patchwork of bilateral transfers under Model 1. 
An international organization could also provide a potential institutional framework for ensuring transfer of technology on which patents have lapsed or which have been developed by governments. While there can be no doubt that much of the technology that will help fight climate change is currently patented (or will be as innovations occur), it must be remembered that a mass of useful technology is already in the public realm with the main barriers to its acquisition and use being the lack of financial, informational and adaptive capacity. International organizations can overcome some of these obstacles by serving as a clearing house of information on relevant technologies.

Unfortunately, 'soft' technology is unlikely to be transferred effectively through compulsory licensing or expropriation by an international governmental agency. At best, an ITTA could develop a facilitative role or oversee such a role for national governments between soft technology holders and potential recipients, and thus only be indirectly involved in the transfer of this kind of technology.

The creation of a new major multilateral institution like the ITTA may also be a source of concern. Industrialized countries have made it clear that they do not wish to see any new multilateral institutions created while many developing countries are concerned with their traditionally weak voice within the more powerful existing institutions; each group might perceive the centralized bargaining strength of an ITTA as a threat, the North with respect to the terms of acquisition and the South with respect to the terms of transfer. There would be a shared concern with the massive inefficiencies that often characterize the operation of such institutions.

The sobering stalemate over the Law of the Sea Convention, directed almost entirely at the deep seabed superstructure including the transfer of technology provisions, and the shape of any revisions which may emerge from ongoing negotiations to save the Convention will be directly relevant to the practicality of the ITTA mechanism. It must, however, constantly be kept in mind that the context is significantly different, with the key difference being that the North perceives a real self-interest in arresting global climate change.

Nonetheless, many Northern companies and governments will oppose such a mechanism because they feel it weakens intellectual property rights and commercial 'freedom'. But compensation is provided and we believe that authoritative public transfers of technology can be warranted when market prices and terms are exorbitant, restrictive or unfair or when the social good is being ignored.

It is also worth putting such opposition in historical perspective. Many Northern states had patent laws designed to promote the local social interest; namely, building and promoting national industrial infrastructure at the expense of technology owned in other states. Only in more modern times are such states emphasizing transnational intellectual property interests in order that their companies can benefit from an internationalized market. Thus, opposition which amounts to treating intellectual property rights as next to 'inherent' is disingenuous. 
Model 3: Direct International Obligations on Private Corporations and Internationally-Sanctioned Restriction of Intellectual Property Rights

\section{Description:}

Instead of focusing on states' obligations to fund or transfer technology, this third model would seek to regulate directly multinational corporations (MNCs). The transnational regulation envisaged by this model would not involve regulation by an international institution apart from perhaps a monitoring and dispute settlement role). Rather, its focus would be on the respective rights and obligations of MNCs and state governments in their dealings with each other. For our purposes, the model would envisage international agreement on obligations of MNCs to transfer environmental technology as a condition of doing business in a country as well as on the related regulatory powers of national governments.

Model 3 proceeds from two premises. The first is that MNCs in today's world function across borders (often strategically to exploit differences between states) and therefore some degree of transnational regulation is thereby necessitated. The second premise is that MNCs function as quasi-sovereign actors in terms of their capabilities and resources; this results in often-unequal bargaining power which is enhanced by the considerable rights they possess by virtue of public and private international law rules and procedures. The goals of this model, then, are to strengthen the bargaining position of private and governmental negotiators in Southern countries in TOET negotiations and to legitimize the acquisition of technology by states on terms that differ from the norm.

This model, like Models 1 and.2, has some precedent on which to build. States in the South have initiated negotiations within UNCTAD on a Code of Conduct on the Transfer of Technology in an effort to mitigate the combined effects of the patent system and 'restrictive business practices' of Northern companies. These factors have often ensured that Southern countries fail to secure any meaningful access to technology before the technology has been rendered obsolete by a new generation of technology.

As well, over the past fifteen years, discussions have taken place on revisions to the Paris Convention for the Protection of Industrial Property. The objective of many Southern states in these negotiations has been to secure international legal recognition of states' rights to undertake policies which prioritize certain national social interests over intellectual property rights.

With this history in mind, Model 3 would modify the international intellectual property regime to respond to the global social interest through the widespread use of greenhouse-related technology. International agreement would be reached on 'legitimate' restrictions to intellectual property rights for certain technologies such as shorter patent protection periods, national compulsory licensing, and at its most stringent, the refusal of patents for certain crucial technologies: Such a regime could also identify the kinds of restrictive business practices (fourteen of which are listed in the current UNCTAD Code draft) which are to be avoided as contractual terms in 
negotiations on the transfer of technology between MNCs and the host state or its local companies.

Strengths and Weaknesses:

The main virtue of this model is that it helps produce a more level playing field in bilateral contractual negotiations between MNCs and countries in the South. As well, it legitimizes national regulatory policies that seek to vindicate the global interest at the same time as their national interest in having access to technology which is not only environmentally friendly but also economically competitive. By adopting an international harmonized standard, companies would not be able to point to failure to meet international intellectual property standards as a reason for not investing or licensing technology.

The model also avoids the creation of a new international institutional 'monster' and for that reason may attract support in both the North and South. It will, however, require substantial international negotiations to determine what technologies will be affected by restricted intellectual property rights and what those restrictions will be.

Problematically, Model 3 really does not displace the free market approach to technology transfer, which we have seen in model 1 has significant flaws. The proposed restrictions on intellectual property rights simply increase the bargaining power of Southern governments in marketplace negotiations over technology transfer. Moreover, while the international agreement required for this model to function would permit national curtailment of intellectual property rights, it does not force countries to do so.

The result will almost certainly be that MNCs will be able to play states off against each other in negotiations, encouraging the development of different levels of intellectual property protection for identified technologies in different states. MNCs will also be in a position to boycott those countries that provide them with the least favourable terms.

Even so, Model 3 will help moderate the concern that Model 1 takes as its staring point business deals arrived at independently in the marketplace. Those deals are likely to be somewhat better if Model 3 is present as a backdrop for negotiations.

Furthermore, agreements secured under Model 3 might provide a body of standards which would guide (and constrain) the activity of an agency like the ITTA proposed in model 2. Model 3 agreements could serve as measuring-sticks for a determination by ITTA as to whether its intervention is necessary with respect to particular technology or whether bilateral arrangements are functioning well enough and should not be disturbed. The Model 3 agreements could also serve as the normative framework for ITTA's own interactions with companies whose technology they seek to acquire or the transfer of which it seeks, as a mediator, to facilitate. 
On the other hand, the presence of the Model 2 agency could also make it more likely that companies will agree to fairer terms in model 3 agreements to avoid the authoritative international acquisition of their technology.

Model 4: An Emissions Trading Scheme - Trading Technology for Emissions Permits

\section{Description:}

This model would require governments to negotiate a global ceiling for annual emissions of greenhouse gases, although we will assume for ease of exposition that the scheme would be limited to $\mathrm{CO} 2$. emissions released through fossil fuel burning. They would then negotiate a criterion (or criteria) for initial allocation to states of permits to emit $\mathrm{CO} 2$. For example, governments might work from the principle that every human being has an equal right to use the global atmosphere and therefore would agree to allow all states equal per capita emissions of $\mathrm{CO} 2$.

Once these negotiations were completed, an emissions trading market would begin. Countries whose actual emissions exceeded their allowable limit could trade with those countries that had a surplus of permits. Given that by and large, the countries in the North have considerably higher per capita energy consumption patterns, the expected result under the Model would be a net transfer of resources to the South.

This model envisions that Southern countries would have technology transferred to them in exchange for their permits. Permit ownership would initially be in the hands of governments but could be acquired by other actors, notably MNCs, with technology to offer in exchange.

As an example then, the United States might acquire technology from MNCs that will help in the development of village solar energy systems and then transfer this technology to India in exchange for permits. On the other hand, the MNC could buy these permits from India with technological assistance and then sell the permits to a Northern government like the U.S.

An international fund/agency would also likely have to operate as a kind of dual regulator and central bank, accumulating fines for breach of trading rules and exceeding emissions levels into a central fund. These accumulated funds could then be used to purchase permits and tighten the market so as to increase the incentives for technological innovation and thereby keep a constant downward pressure on carbon emissions or they could finance independent $R$ \& D designed to produce technology which would then be available to all humankind, unfettered by intellectual property rights.

Strengths and Weaknesses:

One potential benefit of this model is that it could combine technological innovation incentives with cost-effectiveness. The system should provide economic 
incentives to the low-level polluters to keep their emission levels low (more permits to sell) and economic incentives to the high-level polluters to reduce their emissions (decrease their need to buy permits). These incentives could be a powerful tool to encourage countries to do better than required by international regulation.

Another potential benefit is that the model is largely sovereignty-respecting in that sovereign states decide whether and how they will trade. This is particularly true for the Southern states that have a large permit surplus. These states will have more bargaining power here than in any of the other market based models that have been examined.

Finally, and importantly; the model's bilateral emphasis also reduces international bureaucratic involvement.

Unfortunately, the disadvantages seem equally impressive. They can be summarized as (1) excessive complexity, (2) market failure potential and (3) conditionality concerns.

The system proposed faces serious practical problems both in being negotiated and in operation. The greatest difficulties are in fact political, for example, reaching agreement on a total global emissions target. Should carbon dioxide emissions from deforestation be included? Are sinks to be factored in? Should historical emissions or current emissions be considered? Unfortunately, agreement on the allocation of permits will be even more difficult to achieve.

As for the operation of the system, it hinges heavily on effective emissions measurement capabilities, which, it should be noted, itself would involve a prior wholesale transfer of sensitive and patented computer information technology from the North before the system could work. Another practical difficulty is that enforcement, or at least effective monitoring, is crucial with effective procedures themselves being difficult to negotiate.

One could also quite legitimately fear the model's potential for market failures. Small Southern countries with a limited emission permit surplus may have relatively little bargaining power in such a system with Northern interest focused on countries like India and China.

Moreover, the pattern of technology acquisition and development for Southern countries might simply fall short of what is needed to stay within their own emission limits. This could result in Southern countries coming up against a 'growth ceiling' and finding themselves in a future equivalent of the current debt crisis by having to transfer resources to the North to buy back emissions levels or acquire still-needed technology. This problem can potentially be resolved, but once again serious negotiations would be required.

A final problem is related to that of market failure, the problem of conditionality. One can easily imagine the use of bilateral and cartel-like pressuring and conditionalities as mechanisms for both the North and South to achieve other policy 
goals (i.e. enacting domestic economic reforms in the South or charging higher permit prices to the North). Accordingly, it is not clear what the balance of bargaining power will really be. At that point, one must take seriously the lessons of history that indicate in general terms that those who start out more powerful in a market setting end up even more powerful as time goes on.

\section{RECOMMENDATIONS}

The preceding analysis clearly indicates that each of the models surveyed contains some unacceptable flaws. We are unable to support any single one of them as the basis for a technology transfer mechanism under a climate change convention. It is possible, however, that a combination of models, with some important additions, could be acceptable.

Such a technology transfer mechanism would recognize that the free market alone will not do the job. Models 1,3 and 4 illustrate how market imperfections could subvert efforts to protect the global climate. An international institution is required that has the power to ensure that the global interest is given precedence over private interest when the two are in substantial conflict.

This institution, however, must not ignore the market's capacity to promote innovation and efficiency. A cumbersome international bureaucracy will also hinder climate protection efforts.

It is possible to create a technology transfer mechanism that incorporates these considerations while respecting the basic goals and principles advocated earlier. Such a model will not incorporate any of the characteristics outlined in model 4 . We believe that the complexity of this model, and concerns about market failure and conditionality, make it unworkable in the, real world.

Instead, we would support a technology transfer mechanism that combines characteristics of models 1,2 , and 3 .

The proposed technology transfer mechanism would take as its starting point model 1, as epitomized by Article 10 of the revised Montreal Protocol. An international technology transfer fund would be established and it would be financed according to the principles set out in Section Three.

This fund would be used to pursue the goals for technology transfer described in Section Three by doing the following:

- it would finance the incremental costs of the transfer of 'hard' and 'soft' technology, including the increase in cost of purchasing an imported product that does more to reduce carbon dioxide emissions from the burning of fossil fuels than one that does not. (eg. more energy efficient appliances)

- it would provide funding to private businesses and governments in the South to support indigenous $\mathrm{R}+\mathrm{D}$ into technologies that reduce the emission of carbon 
dioxide from the burning of fossil fuels.

These first two categories of projects would account for the vast majority of funds dispersed by this technology transfer fund. A limited number of funds, however, could be used to either (a) support independent international R\&D on energy efficiency and renewable energy technologies that would produce products that would be the common heritage of humanity and therefore not require patent protection, or (b)

provide partial funding for $\mathrm{R}+\mathrm{D}$ projects undertaken by private corporations in the North under the condition that no patents attach to the results.

A separate and much smaller fund would be created to cover any costs incurred in the protection of intellectual property rights through the purchase of patents. This fund would be financed by the Western industrialized countries alone and each country's mandatory contribution would be based on its relative contribution to the climate change problem. Fair levels of compensation should be provided, but some of the money must be tied to future $R+D$ relating to the reduction of carbon dioxide emissions from energy use.

Agreements to transfer technology that have been reached in the marketplace between private technology owning interests and recipients, whether they be governments, corporations or NGOs, should be eligible for assistance from these funds.

The two funds will be administered and overseen by a new international organization like the ITTA described in model 2. It will be controlled, and decisions will be taken, in a manner consistent with the principles outlined in Section Three.

The institution will have the ability to go beyond this administration and oversight role in cases of market failure with regard to certain technologies it defines as critical.

This international institution will have the power to identify such critical technologies and the governments represented in the institution will then have the ability to negotiate and reach agreement on the restriction of intellectual property rights for these technologies as outlined in model 3. These powers should go beyond those outlined in model 3 in the sense that such restrictions of intellectual property rights, once agreed upon within the institution, should not simply be permitted, but should be required.

The international institution would also have the ability to finance the expropriation of certain important technologies that it felt were being transferred inadequately in the marketplace as outlined in model 2.

Finally, however, the international institution would not be responsible for implementation of technology transfer. This would be done by existing multilateral and national institutions with expertise in the area. The role of major multilateral institutions in implementation should be limited to the greatest degree possible in an 
effort to lessen some of the inefficiencies that have often characterized these institutions. It is preferable to do most of the implementation on a bilateral basis. basis between relevant national organizations.

Moreover, we believe that the role of an international clearing-house for up-todate information on relevant technologies need not fall to the ITTA. This job can be adequately handled by existing institutions such as the United Nations Environment Programme, which has already taken on such a role within the Montreal Protocol.

\section{WHERE WE GO FROM HERE: LOGISTICAL AND STRATEGIC CONSIDERATIONS}

The technology transfer mechanism outlined above is certainly more ambitious than what Northern governments are proposing within the climate convention negotiations. For the most part, these governments would like to emulate the Montreal Protocol experience (as defined by model 1) by using the World Bank's Global Environment Facility as an international fund for technology transfer and implementing such a transfer through a combination of the World Bank, UNEP and UNDP.

This vision is unacceptable. While the Montreal Protocol's Ozone Fund remains untested and unproven, it is likely to rely too heavily on the market to be successful. Moreover, we remain extremely sceptical about the World Bank's Global Environment Facility (GEF). While this paper will not examine the weaknesses of the GEF in detail, we fear that it is an undemocratic Northern institution that is likely to be steeped in the World Bank tradition of inefficient and inappropriate technology transfer.

On the other hand, the desire of many Southern countries to have a highly centralized and controlled system of technology transfer that ignores the marketplace is also unacceptable. The market system must be utilized to the greatest extent possible, but mechanisms must exist to deal with the many cases of market failure.

Climate change is a threat that requires new ideas and creative solutions. Technology transfer under a climate change convention must make some break with existing institutions, and standard bargaining positions. This proposal attempts to do that. But a new institution will not come about easily.

The following efforts must be undertaken to help build support for the composite model advocated in this paper:

* work to make it clear that the costs of technology transfer will be less than the costs imposed by climate change and attempts to adapt to it. This can be done in part by encouraging detailed studies within developing countries and the countries of Central and Eastern Europe that would assess the costs of technology transfer. It is likely that these studies will, as in the case of the Montreal Protocol, indicate that the costs of specific projects will be lower than expected and some may even be costeffective. 
* work to build support among various sectors for the broader definition of technology transfer advocated in this paper on both environmental and ethical grounds.

* closely monitor and assess the experience of the Montreal Protocol's Ozone Fund, paying particular attention to its weaknesses and how it could be strengthened.

* play an active role in securing soft legal commitments in future documents that continue to build on those already made in documents like the Noordwijk Declaration and the Ministerial Declaration of the Second World Climate Conference and shift them towards our vision. Doing so will also help keep all governments, Northern and Southern alike, from backpedalling. 